\title{
IDENTIFIKASI PENYEBAB RUSAKNYA HEAVY LIQUID CHAMBER PADA LO PURIFIER MITSUBISHI SJ25T DI MV. JINGU DENGAN METODE FTA
}

\author{
Gangga Putra Mahardika $^{a}$, Agus Tjahjono ${ }^{b}$, Sumardi $^{c}$

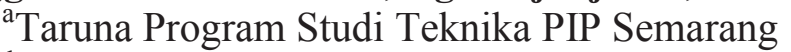 \\ ${ }^{\mathrm{b}}$ Dosen Program Studi Teknika PIP Semarang \\ ${ }^{c}$ Dosen Program Studi Nautika PIP Semarang \\ *e-mail : vbs.dark@gmail.com
}

\begin{abstract}
ABSTRAK
Minyak lumas merupakan kebutuhan yang sangat penting dalam pengoperasian permesinan di kapal baik untuk Mesin Induk maupun permesinan bantu. Maka dari itu sebagian besar kapal niaga dilengkapi dengan pesawat yang dapat menjaga kualitas minyak lumas yang disebut Lube Oil Purifier. Dimana pesawat ini fungsinya untuk membersihkan kotoran maupun kandungan air pada minyak lumas dengan proses purifikasi. Dalam penelitian ini penulis mempunyai beberapa masalah yang menjadi tujuan penulisan: faktor penyebab rusaknya heavy liquid chamber pada Lube Oil Purifier pada saat beroperasi, penilaian dengan metode FTA terhadap pencegahan terjadinya trouble pada Purifier saat beroperasi, dan langkah yang harus dilakukan jika mendeteksi abnormalitas pada purifier untuk mencegah kerusakan Lube Oil Purifier tersebut.

Agar faktor yang dapat menyebabkan rusaknya heavy liquid chamber pada Lube Oil Purifier dan pencegahan terjadinya trouble serta kerusakan dapat diketahui maka dalam karya tulis ini penulis menggunakan analisa dengan metode Fault Tree Analysis (FTA). Metode FTA digunakan dalam menganalisa kejadian kegagalan dalam sistem. Metode FTA dapat didefinisikan sebagai analisa untuk mencari penyebab terjadinya masalah dari masalah puncak hingga menuju akar permasalahan menggunakan diagram pohon kegagalan dengan tujuan mencari faktor terkecil baik dari mesin maupun manusia yang dapat menyebabkan terjadinya suatu kegagalan tersebut. Dari hasil penelitian menggunakan metode FTA maka didapatkan faktor yang dapat menyebabkan kerusakan pada heavy liquid chamber dan trouble yang terjadi pada Lube Oil Purifier. Maka perawatan dan perbaikan pada setiap komponen perlu lebih diperhatikan, hal tersebut dapat dilakukan dengan mengikuti sistem perawatan berencana yang terdapat di setiap kapal yang telah ditentukan oleh perusahaan berdasarkan kebijakan perusahaan, instruction book dan makers.

Selain itu pengawasan pada Lube Oil Purifier yang sedang beroperasi juga diperlukan untuk memantau kondisi pengoperasian. Pada kesimpulan dan saran dikemukakan tentang pentingnya mengadakan perawatan dan pemeriksaan secara rutin terhadap semua bagian yang beresiko menimbulkan trouble dan kerusakan pada Lube Oil Purifier. Bila didapati adanya trouble pada pengoperasian Lube Oil Purifier maka pengoperasian harus segera dihentikan dan dilakukan pengecekan.
\end{abstract}

\section{Kata Kunci: Lube Oil Purifier, heavy liquid chamber, kerusakan}

\section{PENDAHULUAN}

Perkembangan ekonomi dari suatu bangsa sangat dipengaruhi oleh berkembangnya pertumbuhan ekonomi dalam berbagai bidang, salah satunya adalah bidang perdagangan. Bidang perdagangan yang mencakup pada kegiatan ekspor dan impor berbagai macam barang maupun komoditas membutuhkan alat transportasi sebagai sarana pendistribusian. Maka dari itu, alat transportasi atau juga disebut sarana transportasi memiliki peran utama dalam proses pemindahan dan penyebarluasan komoditas yang dihasilkan oleh suatu negara. 
Pada saat ini sarana transportasi sangat bermacam ragamnya, mulai dari transportasi darat, laut maupun udara yang tiap bagian memiliki kelebihan dan kekurangan yang berbeda satu sama lain. Untuk saat ini sarana transportasi yang paling dibutuhkan oleh pelaku ekonomi, terutama dalam perdagangan global adalah sarana transportasi yang dapat mengangkut muatan dalam jumlah yang besar serta ketepatan waktu, murah, dan aman.

Dari penjelasan tersebut di atas, yang mendekati kriteria tersebut adalah transportasi kapal laut. Yang jenisnya bermacam-macam, mulai dari kapal car carrier, log carrier, kapal passenger, kapal container, kapal curah, kapal tanker. Dari tiap jenis kapal dibedakan berdasarkan muatan yang diangkut. Seperti kapal container untuk mengangkut muatan yang dikemas dalam container/peti kemas, kapal curah untuk mengangkut muatan curah, kapal log carrier untuk mengangkut muatan kayu, dan kapal tanker untuk mengangkut muatan minyak. Jenis kapal tersebut dibuat bertujuan untuk mempercepat proses bongkar muat dan mencegah adanya kerusakan pada muatan dengan cara penempatan dan penanganan cargo yang dikhususkan untuk setiap jenis muatan yang dibawa. Banyak terdapat perusahaan besar di negara asing yang bergerak dalam berbagai bidang dengan bermacam-macam jenis kapal yang tersedia yang memberikan jasa transportasi laut, dan salah satu perusahaan pelayaran dalam bidang pengangkutan produk mobil dengan menggunakan kapal Pure Car Carrier adalah NYK Ship Management yang beralamat di 1 Harbourfront Place, \#15-01 Harbourfront Tower One, Singapore yang beroperasi di benua Asia, Amerika Serikat dan beberapa negara di Timur Tengah, pada umumnya jenis muatan yang dikirim oleh pemilik muatan berupa mobil baru, traktor, bulldozer dan bus, serta jenis kendaraan berat militer seperti tank.

Sekarang ini hampir semua kapal niaga yang beroperasi menggunakan low speed two stroke diesel engine yaitu mesin diesel 2 tak kecepatan rendah. sebagai mesin penggerak utama atau juga disebut main engine. Pada MV. Jingu yang memiliki main engine bertipe 7UEC60LA buatan Kobe Diesel Co, Ltd menggunakan 2 macam sistem lubrikasi yang terdiri dari system oil dan cylinder oil. System oil berperan untuk melumasi bagian bergerak mesin seperti crosshead, main bearing, dan camshaft, sedangkan untuk cylinder oil berperan sebagai media pendingin silinder saat terjadinya proses pembakaran dan termasuk consumable oil atau minyak lumas yang dikonsumsi. Penggunaan system oil pada Main Engine sangat berbeda dengan penggunaan cylinder oil dikarenakan system oil bersirkulasi di dalam Mesin Induk untuk melumasi komponen gerak mesin dan kembali lagi ke sump tank yang terletak pada bagian dasar Mesin Induk. Untuk merawat system oil ini agar selalu dalam kondisi baik dan layak untuk proses pelumasan yang optimal, maka pada kapal niaga saat ini disediakan perangkat Lube Oil Purifier untuk membantu menjaga kinerja minyak lumas dengan cara memisahkan minyak lumas dari kotoran dikarenakan efek pengoperasian mesin induk.

Lube Oil Purifier adalah salah satu pesawat bantu yang mendukung operasional kapal dengan fungsi sebagai alat yang menjaga kualitas minyak lumas dengan cara memisahkannya dari kotoran yang terdapat pada minyak lumas. Selama penulis melaksanakan praktek laut (Prala) di MV. Jingu , pada tanggal 17 Juli 2015, setelah selesai pengambilan angka pada parameter flowmeter di kamar mesin terjadi alarm dan didapati pada monitor ruang kontrol adalah alarm abnormal pada Lube Oil Purifier nomor 2. Setelah dilakukan reset pada alarm di panel ruang kontrol, penulis dan Masinis III melakukan pengecekan pada sisi Lube Oil Purifier dan mendapati kerusakan parah pada bagian luar dan juga pada bagian dalam mesin.

Dari hasil percakapan penulis dengan Masinis III yang bertanggungjawab terhadap pesawat Lube Oil Purifier dan data yang didapatkan dari logbook serta dokumen maintenance report tidak ditemukan adanya keterlambatan dalam jadwal perawatan Lube 
Gangga Putra Mahardika ${ }^{\mathrm{a}}$, Agus Tjahjono ${ }^{\mathrm{b}}$, Sumardi $^{\mathrm{c}}$

Oil Purifier, namun Masinis III menyimpulkan bahwa kemungkinan penyebab timbulnya masalah yang terjadi pada pesawat Lube Oil Purifier adalah terdapat komponen rangkaian vertical shaft dan horizontal shaft seperti bearing dan spiral gear yang rusak dan kemudian mempengaruhi putaran bowl menjadi tidak seimbang.

Tujuan penelitian ini adalah untuk mengetahui faktor penyebab rusaknya heavy liquid chamber pada Lube Oil Purifier pada saat beroperasi. Kemudian dengan metode analisa Fault Tree Analysis diperoleh urutan kejadian puncak hingga faktor penyebab terkecil dari kerusakan heavy liquid chamber untuk menjadi penelitian penulis selama melaksanakan praktek laut.

\section{METODE PENELITIAN}

Penelitian tentang Lube Oil Purifier dilakukan selama sembilan bulan ketika masa Proyek Laut di kapal kedua berlangsung, yaitu terhitung mulai tanggal 11 Februari 2015 sampai dengan tanggal 13 November 2015. Penelitian dilakukan saat melaksanakan Proyek Laut selama berada di atas MV. Jingu, merupakan salah satu kapal jenis Pure Car Carrier milik PT. NYK Ship Management. Pada kapal Pure Car Carrier ini terdapat car deck dengan jumlah 12 lantai untuk penempatan muatan yaitu jenis mobil, bus, serta kendaraan dan alat berat lain yang selalu digunakan maksimal menurut penempatannya dimana terdapat lubang dan shackle yang menempel pada lantai untuk pengamanan muatan dengan cara lashing. Pada tiap lantai atau deck terbagi menjadi 2 sampai 4 palka yang dipisahkan oleh watertight door yang dapat mencegah menyebarnya air ke seluruh car deck jika terjadi keadaan darurat bila terdapat banjir di ruang muatan.

Saat pelaksanaan penelitian selama penulis melaksanakan praktek di atas kapal, kapal telah mengangkut dan membongkar berbagai macam kendaraan dari satu negara ke negara lainnya dengan baik, aman dan tepat waktu sesuai waktu yang sudah ditentukan, adapun jenis kendaraan yang dimuat adalah sedan, multi purpose vehicle, sport utility vehicle, mini sport utility vehicle, bus, bulldozer dan tractor. Karena jarak tempuh pelayaran dan tujuan yang ditempuh kapal ini sangat bervariasi dan sangat jauh hingga harus menghabiskan waktu lebih dari seminggu untuk sampai di tempat pemuatan maupun pembongkaran muatan, maka sangatlah penting untuk menjaga mengoptimalkan kondisi mesin penggerak utama maupun pemesinan bantu lainnya untuk menunjang lancarnya pelayaran. Peranan kualitas minyak lumas sangat penting untuk pengoperasian mesin penggerak utama atau main engine. Berdasarkan hal tersebut, pada kapal ini terdapat pesawat bantu Lube Oil Purifier yang termasuk sistem pesawat bantu pendukung lancarnya pelayaran dengan membantu menjaga kualitas minyak lumas.

Pengamatan dan pandangan terhadap data yang ada mulai dari pokok permasalahan yang terjadi, membaca kumpulan data baik yang didapatkan dari wawancara, kajian pustaka, maupun hasil dari lapangan, dikaji berdasarkan teori yang dapat memberikan pemecahan masalah yang terbaik sehingga permasalahan yang timbul dapat terselesaikan dengan cepat, tepat dan aman. Adapun metode yang digunakan untuk menganalisa data dalam penelitian adalah metode Fault Tree Analysis. Metode ini memaparkan semua peristiwa yang terjadi atau yang mungkin akan menjadi penyebab kerusakan kapal. Hal tersebut dijelaskan melalui pembuatan pohon kegagalan terhadap kerusakan Lube Oil Purifier dalam proses purifikasi.

FTA didefinisikan sebagai sistem dan bentuk penilaian dari perancangan atau proses yang telah ada atau operasi dengan maksud untuk mengidentifikasi dan mengevaluasi masalah yang mewakili kejadian yang menyebabkan pengaruh kinerja sistem. Dengan kata lain, metode ini dapat digunakan untuk mencari troubleshooting mesin, sehingga semua kemungkinan kerusakan dapat teratasi dengan cepat dan tepat. Untuk menentukan faktor penyebab rusaknya heavy liquid chamber pada Lube 
Oil Purifier, di sini penulis akan menggunakan metode FTA sebagai alat yang dipakai untuk mengidentifikasi kegagalan yang menjadi penyebab terjadinya undesired event, dan probabilitas terjadinya undesired event tersebut. Mencari penyebab undesired event adalah dengan cara melakukan analisa dari atas ke bawah (top-down approach). Dengan melakukan analisa dari kejadian puncak menuju akar masalah, maka dapat diketahui bagian mana dari sistem yang gagal dan perlu dilakukan tindakan perbaikan dan pencegahan berdasarkan kegagalan yang ada agar kejadian yang sama tidak terulang.

Fault tree dibangun berdasarkan pada undesired event yang terjadi pada kegagalan sistem. Hanya bagian tertentu dari sistem yang berhubungan beserta kegagalan yang ada, yang dipakai untuk membangun fault tree. Pada satu sistem bisa terdapat lebih dari satu undesired event dan masing-masing undesired event mempunyai representasi fault tree berbeda yang disebabkan faktor atau bagian sistem dan kegagalan yang mengarah pada satu kejadian berbeda dengan lainnya. Pada fault tree, undesired event puncak yang akan dianalisa disebut juga top event.

\section{HASIL DAN DISKUSI}

Di dalam identifikasi kerusakan heavy liquid chamber pada saat pengoperasian Lube Oil Purifier, penulis menggunakan data yang didapatkan pada saat pembongkaran Lube Oil Purifier untuk dianalisa menggunakan fault tree analysis. Sebelum mencari faktor penyebab kerusakan heavy liquid chamber, penulis terlebih dahulu membuat kejadian puncak dari pokok permasalahan sebagai top event dari pembuatan bagan fault tree, yaitu rusaknya heavy liquid chamber. Bagan dari fault tree ini terdiri dari kejadian puncak (top event), intermediate event, dan basic event adalah yang terkecil sehingga menghasilkan minimal cut set yaitu sebutan untuk faktor terkecil dari fault tree itu sendiri. Masingmasing dari kejadian tersebut memiliki simbol sendiri pada bagan fault tree (Gambar $1)$.

Dari top event pertama yaitu rusaknya heavy liquid chamber (Gambar 2), didapatkan kejadian penyebab yaitu putaran bowl tidak seimbang, tidak seimbangnya putaran bowl ini dapat disebabkan disebabkan oleh kondisi spiral gear pada horizontal shaft yang terdapat goresan (Gambar 3) sehingga mempengaruhi pinion pada vertical shaft dan berputar tidak seimbang. Adanya goresan pada spiral gear ini dapat disebabkan oleh kurangnya pengawasan pada saat perawatan purifier.

\section{KESIMPULAN}

Faktor yang menyebabkan kerusakan heavy liquid chamber pada Lube Oil Purifier adalah tidak seimbangnya putaran bowl yang disebabkan adanya kerusakan pada spiral gear sehingga menyebabkan putaran vertical shaft tidak seimbang, hal ini dapat dicegah dengan meningkatkan pengawasan dan pemeriksaan kondisi bagian Lube Oil Purifier setiap mengadakan perawatan.

\section{DAFTAR PUSTAKA}

Fuad, Anis. 2014. Panduan Praktis Penelitian Kualitatif. Yogyakarta: Graha Ilmu

W. E. Vesely, U.S. Nuclear Regulatory Commission, F. F. Goldberg, U.S. Nuclear Regulatory Commission, N. H. Roberts, University of Washington, D. F. Haasl, Institute of System Sciences, Inc., 2012, Fault Tree Handbook, U.S.PEN Government Printing Office, Washington DC

Vermeire, M. B. 2012. Everything You Need to Know About Marine Fuels, Chevron Global Marine Products. Belgium

NYK Maritime College. 2012. NYK Engine Cadet Course Hand-out. NYK Ship Management

Vidak, Nives. 2016. Marine Engineering Course, Sveučilište u Dubrovniku. Dubrovnik

Mitsubishi Selfjector Series.1992. Instruction Manual For Purifier SJ20T 60T, Kanasashi Co., Ltd. Design Department. Kanagawa 